\title{
A atuação do Estado Brasileiro nas Políticas Públicas para Educação Profissional nos governos Fernando Henrique Cardoso (1995-2002) e Luiz Inácio Lula da Silva (2003-2010)
}

The performance of the Brazilian State in Public Policies for Professional Education in governments Fernando Henrique Cardoso (1995-2002) and Luiz Inácio Lula da Silva (2003-2010)

La actuación del Estado Brasileño en las Políticas Públicas para Educación Profesional en los gobiernos Fernando Henrique Cardoso (1995-2002) y Luiz Inácio Lula da Silva (2003-2010)

Arão Davi Oliveira ${ }^{1}$

Celeida Maria Costa de Souza e Silva ${ }^{1}$

\section{DOI: http://dx.doi.org/ 10.20435/serie-estudos.v24i50.1202}

Resumo: Este artigo discute as principais políticas públicas voltadas à educação profissional dos governos Fernando Henrique Cardoso (1995-2002) e Luiz Inácio Lula da Silva (2003-2010) no contexto da fase de acumulação flexível do capital. Focaremos nossas discussões nos programas PLANFOR e PROEP para o período de 1995 a 2002; para o período de 2003 a 2010, nos programas e ações: fortalecimento e expansão da Rede Federal de Ensino Técnico, criação da Rede e-TEC Brasil, no programa Brasil Profissionalizado; por fim, no acordo de gratuidade com o Sistema S. Essa é uma pesquisa documental e bibliográfica ancorada nos conceitos de "Estado" de Gramsci (1991). É possível afirmar que, no período estudado, as diferentes articulações entre a educação e o trabalho foram mediadas pelo Estado em âmbito federal, por meio de políticas públicas voltadas à educação profissional, as quais atenderam, em maior parte, aos interesses de organismos internacionais e grupos de empresários nacionais os quais requisitavam força de trabalho mais flexível adaptada às novas demandas do sistema produtivo na fase de acumulação flexível do capital.

Palavras-chave: Políticas Públicas Educacionais; educação profissional; acumulação flexível do capital.

\footnotetext{
${ }^{1}$ Universidade Católica Dom Bosco (UCDB), Campo Grande, Mato Grosso do Sul, Brasil.
} 


\begin{abstract}
This article discusses the main public policies focused on the professional education of the governments Fernando Henrique Cardoso (1995-2002) and Luiz Inácio Lula da Silva (20032010 ) in the context of the phase of flexible capital accumulation. We will focus our discussions on the PLANFOR and PROEP programs for the period 1995-2002; already for the period from 2003 to 2010 we will focus on the programs and actions: strengthening and expansion of the Federal Network of Technical Education, creation of e-TEC Brazil Network, in the Brasil Profissionalizado program; finally, in the agreement of gratuity with Sistema S. This is a documentary and bibliographical research anchored in the concepts of "State" of Gramsci (1991). It is possible to affirm that in the studied period the different articulations between education and work were mediated by the State at the federal level through public policies focused on professional education, which mostly served the interests of international organizations and groups of entrepreneurs which required a more flexible labor force adapted to the new demands of the productive system in the phase of flexible capital accumulation.
\end{abstract}

Keywords: Public Educational Policies; professional education; flexible capital accumulation.

Resumen: Este artículo discute las principales políticas públicas para la educación profesional de los gobiernos Fernando Henrique Cardoso (1995-2002) y Luiz Inácio Lula da Silva (2003-2010) en el contexto de la fase de acumulación flexible del capital. Centraremos nuestras discusiones en los programas PLANFOR y PROEP para el período de 1995 a 2002; para el período de 2003 a 2010, en los programas y acciones: fortalecimiento y expansión de la Red Federal de Enseñanza Técnica, creación de la Red e-TEC Brasil, en el programa Brasil Profesionalizado; finalmente, en el acuerdo de gratuidad con el Sistema S. Es una investigación documental y bibliográfica anclada en los conceptos de "Estado" de Gramsci (1991). Se puede afirmar que en el período estudiado, las diferentes articulaciones entre la educación y el trabajo fueron mediadas por el Estado en ámbito federal por medio de políticas públicas para la educación profesional que atendieron, en mayor parte, los intereses de organismos internacionales y grupos de empresarios nacionales, los cuales exigen fuerza de trabajo más flexible adaptada a las nuevas demandas del sistema productivo en la fase de acumulación flexible del capital.

Palabras clave: Políticas Públicas Educacionales; educación profesional; acumulación flexible del capital.

\title{
1 INTRODUÇÃO
}

O presente trabalho foi realizado com apoio da Coordenação de Aperfeiçoamento de Pessoal de Nível Superior - Brasil (CAPES) - Código de Financiamento 001. Resulta de uma pesquisa desenvolvida no Programa de PósGraduação- Mestrado e Doutorado- em Educação da Universidade Católica Dom Bosco (PPGE/UCDB). Vincula-se à Linha de Pesquisa Política, Gestão e História da Educação e ao Grupo de Pesquisa Políticas de Formação e Trabalho Docente na Educação Básica (GEFORT). Objetivamos discutir as principais políticas públicas voltadas à educação profissional dos governos Fernando Henrique Cardoso (19952002) e Luiz Inácio Lula da Silva (2003-2010), no contexto da fase de acumulação 
flexível do capital. É uma pesquisa bibliográfica e documental e se apoia no conceito de estado teorizado por Gramsci (1991).

As políticas públicas voltadas para educação profissional operacionalizam a mediação que o Estado pratica entre os interesses da burguesia, no sentido em que promove a educação profissional que as empresas necessitam, e, em certa medida, promove uma inclusão dos jovens ao mundo do trabalho dominado por uma determinada classe.

Para Ramos (2012), a sociedade civil presente anteriormente apenas na estrutura econômica, ao estender sua atuação passa a figurar na dimensão do Estado junto com a sociedade política. Essa última, com poder sobre os dispositivos jurídicos, passa a configurar o Estado stricto sensu ou governo. Assim, "a concepção de Estado então se amplia, juntamente com suas funções que passam a ser hegemônicas revestidas de coerção, e implica tanto na superestrutura política e jurídica, quanto a própria economia" (RAMOS, 2012, p. 13).

Essa concepção de Ramos (2012), parte do entendimento de "Estado educador" de Gramsci (1991, p. 91), o qual tem por finalidade "adequar a "civilização" e a moralidade das mais amplas massas populares às necessidades de desenvolvimento continuado do aparelho econômico de produção, portanto de elaborar, também fisicamente, tipos novos de humanidade.

Isso perpassa, também, por uma relação de atendimento dos governantes às demandas das classes dirigentes, representadas em maior número por grupos de empresários. Sob esta ótica, Gramsci estabelece sua concepção de Estado, como "todo o complexo de atividades práticas e teóricas com as quais a classe dirigente justifica e mantém não só o seu domínio, mas consegue obter o consentimento ativo dos governados" (GRAMSCl, 1991, p. 91).

\section{EDUCAÇÃO PROFISSIONAL NO GOVERNO FERNANDO HENRIQUE CARDOSO (1995-2002)}

A educação profissional no governo Fernando Henrique Cardoso (19952002) abrangia, também, a qualificação e requalificação profissional coordenada principalmente pelo Ministério do Trabalho e Emprego (MTE), em programas como o Plano Nacional de Qualificação do Trabalhador (PLANFOR) e o Programa de Expansão da Educação Profissional (PROEP), os quais tiveram, no Decreto n. 2.208/1997, o suporte jurídico para materializar uma formação especificamente 
aligeirada, desarticulada com a educação básica, calcada nos conceitos de competência, empregabilidade e polivalência.

Os organismos multilaterais, como o Banco Mundial (BM), que financiam projetos sociais em países da América Latina e Caribe, mostram textualmente a importância que depositam sobre a educação básica. Em 1995, esse organismo publicou um documento intitulado "Prioridades y Estrategias para La Educación", estabelecendo suas Prioridades e Estratégias para investimento na educação, no qual aponta para uma formação mais polivalente adaptável aos novos modelos de organização produtiva flexível.

Esses atributos incluem um nível básico de competência em áreas gerais tais como as habilidades verbais, computacionais, comunicacionais e a resolução de problemas. Essas competências podem ser aplicadas a uma grande variedade de empregos e permitir as pessoas adquirir habilidades e conhecimentos específicos orientados para o trabalho, quando estiveram no local de trabalho. Em geral esse nível básico inclui cerca de oito anos de escolaridade. (BANCO MUNDIAL, 1995, p. 63).

Envolto às influências de representantes do capital internacional e nacional (MELO, 2010), destaca-se o pioneirismo e o alinhamento do documento publicado em 1993 pela Confederação Nacional da Indústria (CNI), intitulado "Educação Básica e Formação Profissional: uma visão dos empresários" (EBFP), com o texto que seria aprovado na Lei n. 9.394/1996 de Diretrizes e Bases da Educação Nacional (LDBEN). Esse documento, EBFP, expressa o desejo dos empresários nacionais com relação às políticas educacionais que seriam formuladas a partir daquele ano. "Demonstra a sintonia existente entre as demandas internacionais, no caso específico, as advindas da Conferência Mundial de Educação para Todos, realizada em Jontiem, Tailândia, 1990, e as demandas da produção, no caso da ênfase no conceito de empregabilidade" (MELO, 2010, p. 13).

Interpretando o relatório de Jacques Delors para Organização das Nações Unidas para a Educação, Ciência e Cultura (UNESCO), publicado no Brasil em 1998, com o título "Educação: um tesouro a descobrir", e que resultou dos trabalhos desenvolvidos pela Comissão Internacional sobre a Educação para o século XXI da UNESCO no período de 1993 a 1996, Silva (2007, p. 114), afirma:

A finalidade de uma educação que se volta para o "aprender a fazer" possui como referência a noção de competências e vincula a educação diretamente às razões do mercado de trabalho. Assim, toda a educação básica deveria 
ter como um de seus pilares o aprender a fazer, que, mesmo sendo indissociável do aprender a conhecer, "está mais estreitamente ligada à questão da formação profissional: como ensinar o aluno a pôr em prática os seus conhecimentos e, também, como adaptar a educação ao trabalho futuro quando não se pode prever qual será a sua evolução".

A nova forma de ser do trabalhador para adaptar-se às novas demandas da produção flexível "tem como centralidade a formação de habilidades, atitudes, competências, disponibilidades, que se encontram legitimadas nos pilares da educação para o século XXI" (DELORS, 1998). A educação proposta no relatório de Delors (1998) torna o sistema educativo um mecanismo de transformar a massa trabalhadora em força de trabalho polivalente e adaptável ao avanço tecnológico (MELO, 2010, p. 203).

Para Frigotto, Ciavatta e Ramos (2012), esse ideário teve, nas noções de "empregabilidade" e "competências", um importante aporte ideológico, justificando, dentre outras iniciativas, projetos fragmentados e aligeirados de formação profissional, associados aos princípios de flexibilidade dos currículos e da própria formação. No dizer desses autores:

Essa e outras avaliações demonstravam que o procedimento do MEC e do MTE, o primeiro pela reforma da educação profissional e incentivos do PROEP e o segundo pelo PLANFOR, visava atender a demandas por qualificação e (re) qualificação profissional da população adulta de baixa escolaridade através de uma rede específica de cursos de qualificação profissional de curta duração (educação profissional básica) completamente dissociados da educação básica e de um plano de formação continuada. (FRIGOTTO; CIAVATTA; RAMOS, 2012, p. 36).

Importante lembrar que foi nesse governo que se efetivou a descentralização da administração com a reforma do aparelho institucional, também, em busca de eficiência na gestão da educação, "na esfera da administração, a atual tendência de inovação na gestão da educação recorre à defesa da autonomia das unidades-fim e à consequente descentralização/desconcentração dos sistemas como mecanismos para a melhoria da qualidade do ensino público" (ADRIÃO, 2006, p. 25).

O Governo de Fernando Henrique Cardoso (1995-2002) tem no Planfor sua maior política pública em atendimento à educação profissional. Esse projeto foi iniciado em 1996, prolongando-se até 2003. 
Segundo Kuenzer (2006), o Banco Mundial não renovou o financiamento desse programa no governo posterior devido à falta de contrapartida exigida pelo banco. Teve como objetivo a democratização ao acesso à formação profissional para a população socialmente carente, desempregados, autônomos e pequenos produtores (BRASIL, 1999). Essas habilidades seguem detalhadas no documento "Emprego no Brasil, diagnóstico e políticas do Ministério do trabalho" (MTB), atual Ministério do Trabalho e Emprego (MTE), com o seguinte texto:

I. avanço conceitual, compreendendo a construção e consolidação de um novo enfoque conceitual e metodológico da EP (educação profissional), orientada pela efetiva demanda do setor produtivo (reunindo interesses e necessidades de trabalhadores, empresários, comunidades), com vistas a elevar a produtividade e qualidade do trabalho, melhorar empregabilidade do trabalhador e condições de vida da população; Il. articulação institucional, relativa à mobilização, integração e fortalecimento de uma rede nacional de EP, integrada por entidades públicas e privadas com infraestrutura e experiência na área, tais como: escolas técnicas federais/estaduais, universidades, Sistema S, ONGs, sindicatos, fundações, ensino livre; III. apoio à sociedade civil, com foco na ampliação da oferta, por meio dessa rede, de EP contínua e flexível, suficiente para qualificar/requalificar pelo menos 20\% da PEA (População Economicamente Ativa, maior de 14 anos) ao ano, especialmente de grupos que tradicionalmente têm menor chance de acesso a ações de qualificação e requalificação profissional. (BRASIL, 1998, p. 13).

O caráter utilitarista dado à educação profissional por esse programa se confirma pela desvinculação do entendimento do trabalho como princípio educativo das políticas de educação profissional, a priorização de uma formação acelerada nos moldes dos princípios da competência e polivalência; sendo assim, os investimentos do Planfor foram voltados para cursos de formação inicial e continuada (FIC), caracterizados por essa autora por serem de curta duração e não agregarem qualidade à educação, pois "esse programa envolveu 15,3 milhões de trabalhadores nos Planos de Qualificação Profissional [...]. Ao mesmo tempo, a carga horária média dos cursos oferecidos passou de 150 horas para 60 horas médias [...]" (KUENZER, 2006, p. 888).

Para financiar a reforma na educação profissional, o governo Fernando Henrique Cardoso (1995-2002) firmou acordo com o Banco Interamericano de Desenvolvimento (BID) implementando, em 10 de setembro de 1997, o Programa de Expansão da Educação Profissional (PROEP) por meio da Portaria Ministério 
da Educação (MEC) n. 1.005. O acordo de financiamento era dividido da seguinte forma: $50 \%$ do BID; $25 \%$ do MEC e $25 \%$ do MTE por meio do Fundo de Amparo ao Trabalhador (FAT). O PROEP teve por objetivo "financiar a expansão física da Rede de Educação Profissional pública (estados e municípios) ou privada, e não mais para investir na expansão da Rede Federal" (BRASIL, 2014, p. 13).

O Decreto n. 2.208/1997 teve como principal proposta a Educação Profissional e Tecnológica (EPT) e o Ensino médio, "que, a partir de então, passaram a percorrer trajetórias separadas e não equivalentes. E que foi por meio dele que se criaram as condições para a negociação e implementação do PROEP, em atenção às exigências do Banco Mundial" (KUENZER, 2006, p. 888).

Essa alteração provocou mudanças no ensino técnico que passou a ser dividido em três níveis: Básico, independe da escolaridade anterior; o Técnico, que supõe o nível médio; e o Tecnológico, que são cursos superiores de curta duração. "A novidade é a criação de um nível básico, dentro do ensino técnico, que independe da escolaridade do aluno" (SHIROMA; MORAES; EVANGELISTA, 2002, p. 77).

A educação profissional teve sua função deslocada com relação ao sistema educacional anterior ao Decreto 2.208/2007 e aos programas PROEP e PLANFOR, no sentido em que "passou a ser orientada para os programas de capacitação em massa" (RAMOS, 2014, p. 35).

Embora façamos uma crítica, por não coadunarmos com a forte transferência de recursos públicos para iniciativa privada para o financiamento da educação profissional (EP), afirma Moura (2007, p. 17) que "é necessário reconhecer que a reforma da EP e o PROEP foram extremamente coerentes com a lógica neoliberal que os patrocinou, de forma que, ao serem analisados a partir dessa perspectiva, aparecem como muito eficientes".

Na visão de Deitos (2005, p. 320), o social-liberalismo educacional "revisitado" e implementado pelo governo Fernando Henrique Cardoso (1995-2002), como política educacional nacional, sustenta a "necessidade de enfrentar novos padrões de produtividade e competitividade, impostos pelo avanço tecnológico, está levando à redescoberta da educação como componente essencial das estratégias de desenvolvimento" (OFFE, 1990, p. 41).

Os elementos presentes nas políticas educacionais do Governo Fernando Henrique Cardoso (1995-2002) e sua vinculação com a base material produtiva de uma economia capitalista foram assim elencados por Ball (2002, p. 110): 
1- A melhoria da economia nacional por meio do fortalecimento dos vínculos entre escolaridade, emprego, produtividade e comércio. 2- A melhoria do desempenho dos estudantes nas habilidades e competências relacionadas ao emprego. 3- A obtenção de um controle mais direto sobre o currículo e a avaliação. 4- A redução dos custos da educação suportados pelos governos. 5 - O aumento da participação da comunidade local a partir de um papel mais direto na tomada de decisões relacionadas com a escola e através da pressão popular por meio da livre-escolha de mercado.

Para Oliveira (2009, p. 203), o governo Fernando Henrique Cardoso (19952002) utilizou a lógica do "recurso à racionalidade técnica" para orientar as políticas sociais. Por isso, "Muitos elementos trazidos por essas reformas foram duramente criticados pelos movimentos sociais que estiveram na base eleitoral do presidente Lula" (OLIVEIRA, 2009, p. 202). Isso, na visão de Pochmann (2010, p. 648), promoveu uma diminuição na mobilidade social, só superada no governo Luiz Inácio Lula da Silva (2003-2010).

\section{A EDUCAÇÃO PROFISSIONAL NO GOVERNO LUIZ INÁCIO LULA DA SILVA (2003-2010)}

As principais diferenças das políticas do Estado brasileiro para EPT, nos governos Fernando Henrique Cardoso (1995-2002) e Luiz Inácio Lula da Silva (2003-2010), giram em torno do modelo de estado que praticaram. No caso do primeiro, o modelo de Estado foi a ortodoxia neoliberal que tem, no entender de Bresser-Pereira (2010, p. 32), as seguintes características:

1 - Nenhum papel econômico para a nação ou para estratégias nacionais de desenvolvimento. 2 - Reforma que reduzem o tamanho do Estado e desregulam os mercados. 3 - As instituições fundamentais para promover o crescimento são os direitos de propriedade e os de contrato. 4 - Papel mínimo do Estado no investimento e na política industrial.

Observando as características da ortodoxia neoliberal, podemos entender o forte financiamento internacional na educação brasileira e a formação de força de trabalho generalista em cursos obrigatoriamente desvinculados com ensino médio.

O modelo de Estado neodesenvolvimentista do governo Luiz Inácio Lula da Silva (2003-2010) tem, na visão de Bresser Pereira (2010, p. 32), as seguintes características: 
1- A nação é o agente que define a estratégia nacional de desenvolvimento. 2 - Reformas que fortalecem o Estado e regulam os mercados. 3 - As instituições chave para promover o crescimento é a estratégia nacional de desenvolvimento. 4- Papel moderado no investimento e na política industrial; grande papel na redistribuição.

Para Mercadante Oliva (2010), o neodesenvolvimentismo do período 2003 a 2010 promoveu crescimento econômico priorizando a distribuição de renda. Para esse autor, "houve uma retomada do processo de consolidação do sistema de proteção social, consagrado pela Constituição de 1988 nas áreas clássicas do Welfare State (educação, saúde, previdência e assistência social)" (MERCADANTE OLIVA, 2010, p. 23).

No governo Luiz Inácio Lula da Silva (2003-2010), houve uma mudança na concepção de desenvolvimento sob o controle do Estado. Nesse processo de fortalecimento de controle e definição da agenda do Estado brasileiro sobre a economia, enfraquecido pelo projeto neoliberal do governo anterior. Morais e Saad-Filho (2011, p. 520) asseveram que esse novo-desenvolvimentismo tem por objetivo "representar uma nova estratégia de desenvolvimento, superando o nacional-desenvolvimentismo tradicional e adequando os seus princípios às novas realidades emergentes da revolução tecnológica e da globalização". Esse entendimento econômico defende a necessidade de romper com as políticas macroeconômicas neoliberais.

Para Mercadante Oliva (2010), a priorização de políticas sociais promovidas pelo neodesenvolvimentismo do governo Luiz Inácio Lula da Silva (2003-2010) configurou-se em um dos eixos estruturadores do desenvolvimento econômico do Brasil desse período. Nas palavras desse autor, foi uma "estratégia por meio da qual se conjugou, com enorme êxito, estabilidade econômica e crescimento acelerado, distribuição de renda e ampliação do mercado interno de consumo de massa, inclusão social e promoção da cidadania" (MERCADANTE OLIVA, 2010, p. 14).

O PLANFOR foi substituído em 2003 pelo Plano Nacional de Qualificação (PNQ), executado no âmbito do MTE, o qual não será abordado com detalhes por não fazer parte da proposta neste artigo. Esse plano foi menos audacioso, mas manteve o mesmo problema da não articulação com o sistema educacional. Já o PROEP, que não investia na expansão da Rede Federal, mas sim financiava a expansão física da Rede de Educação Profissional pública de estados e municípios 
ou privada, foi incorporado pelo programa de expansão da Rede Federal de Ensino Técnico iniciada em 2003, sobretudo pós Decreto n. 5.154/2004.

A dualidade prescrita a partir do Decreto 2.208/1997 sofreu revogação e se confirmou no governo Luiz Inácio Lula da Silva (2003-2010), com o Decreto $5.154 / 2004$, que regulamentou as formas de oferecimento de educação profissional como sendo: integrada, concomitante e subsequente.

Assim, embora a superação da dualidade entre trabalho intelectual e manual esteja indicada na legislação, na prática, em que a dualidade efetivamente ocorre a partir da apropriação privada dos meios de produção, ela se acentua pelo rompimento da relação entre qualificação e ocupação, decorrente das novas formas de organizar e gerir o trabalho no regime de acumulação flexível (BREMER; KUENZER, 2012, p. 6).

No dizer de Frigotto, Ciavatta e Ramos (2005) esse Decreto objetivou resgatar o disposto no $\S 2$ - do Art. 36 da LDB, que afirma: "o ensino médio, atendida à formação geral do educando, poderá prepará-lo para o exercício de profissões técnicas". Isso significou "reconhecer o ensino médio como uma etapa formativa em que o trabalho como princípio educativo permita evidenciar a relação entre o uso da ciência como força produtiva e a divisão social e técnica do trabalho" (FRIGOTTO; CIAVATTA; RAMOS, 2005, p. 11).

Em estudo publicado pelo Instituto de Pesquisa Econômica Aplicada (IPEA) no ano de 2014, intitulado "Pronatec: múltiplos arranjos e ações para ampliar o acesso à educação profissional" consta que o Decreto 5.154/2004 foi considerado como uma forma de dar "flexibilidade à educação profissional, especialmente em sua articulação com o nível médio, e dá liberdade às escolas e aos Estados (no caso do nível médio) de organizar a sua formação" (BRASIL, 2014, p. 13-4).

Após o Decreto 5.154/2004, a educação profissional poderia ser desenvolvida como formação inicial e continuada para trabalhadores na educação de Jovens e Adultos (EJA); técnica de nível médio; e tecnológica de graduação e pós-graduação (BRASIL, 2014, p. 13-4).

Com a retomada do crescimento econômico a partir do ano de 2004, os governos do Partido dos Trabalhadores, que assumiram o poder a partir de 2003, patrocinaram forte investimento na educação profissional (gráfico 1), destacadamente por meio das seguintes ações: expansão da Rede Federal de Ensino Técnico iniciada em 2003, com a criação de 214 novas unidades até o ano de 2010; criação 
do Programa Brasil Profissionalizado por meio do Decreto 6.302 de dezembro de 2007, amparado no Plano de Desenvolvimento da Educação (PDE); criação do Programa Escola Técnica Aberta do Brasil (e-Tec Brasil), que oferta cursos de nível médio a distância, por meio do Decreto n. $6.301^{2}$, de 12/12/2007, no contexto de uma parceria entre a Secretaria de Educação Profissional e Tecnológica (SETEC) e a Secretaria de Educação a Distância (SEED); por fim, com o "Acordo de Gratuidade com o Sistema S" firmado em 2008, entre o Governo Federal e, inicialmente, com Serviço Nacional de Aprendizagem do Comércio (SENAC) e Serviço Nacional de Aprendizagem Industrial (SENAI) para oferta gratuita de cursos de formação inicial e continuada (FIC), que são de curta duração, de 160 horas.

Gráfico 1 - Execução orçamentária do MEC: sub-função ensino profissional (2003-2012). Em R\$ milhões, valores correntes

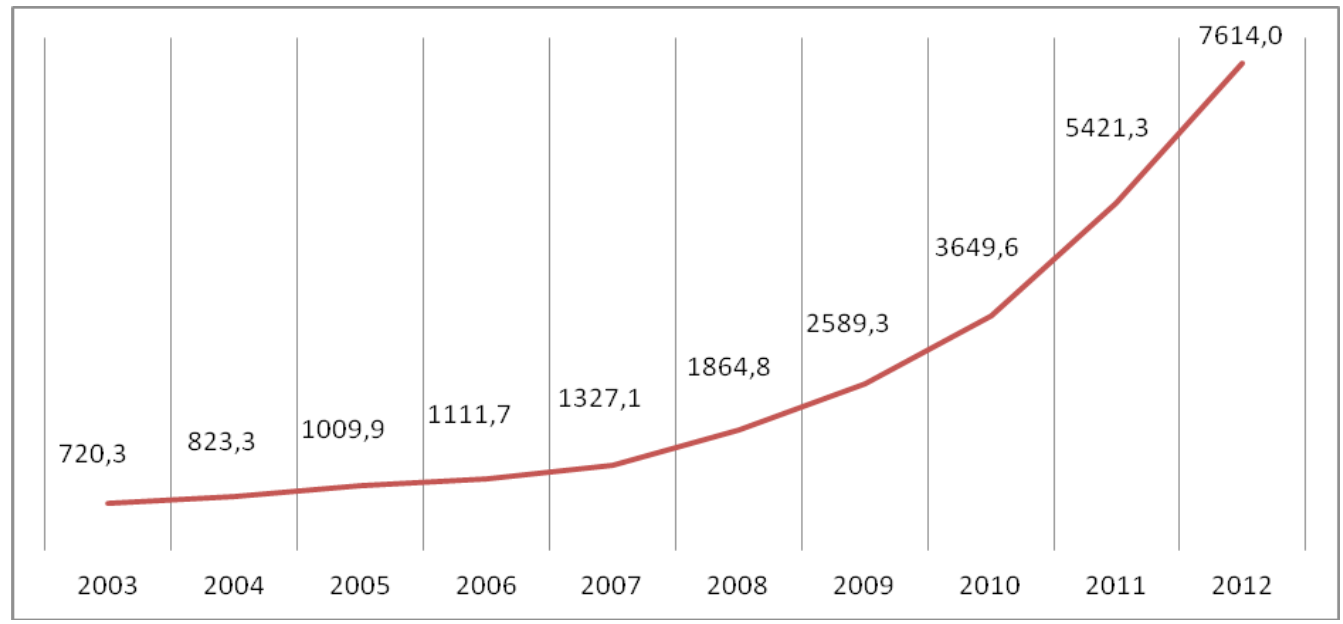

Fonte: Instituto de Pesquisa Econômica Aplicada (BRASIL, 2014). Adaptado pelos autores em 2015.

A expansão da rede federal de educação profissional e técnica tinha como impedimento a Lei 8.948 de 1994, traduzida, especificamente, na palavra "somente" presente no parágrafo $5^{\circ}$ do Art. $3^{\circ}$, escrito como segue: "a expansão da oferta de educação profissional, mediante a criação de novas unidades de ensino por parte da União, somente poderá ocorrer em parceria com Estados, Municípios, Distrito Federal ${ }^{3}[\ldots]^{\prime \prime}$ (BRASIL, 1994, grifo nosso).

\footnotetext{
${ }^{2}$ Alterado pelo Decreto n. 7.589, de 26 de outubro de 2011, no governo Dilma Roussaeff.

${ }^{3} \S 5$ o acrescido pela Lei n. 9.649, de 27/05/1998, governo Fernando Henrique Cardoso.
} 
O parágrafo $5^{\circ}$ do Art. $3^{\circ}$, dificultava os planos do Governo Luiz Inácio Lula da Silva em promover uma expansão da Rede de EPT, e foi alterado pela Lei 11.195, em 18 de novembro de 2005, passando a vigorar com o seguinte texto: "a expansão da oferta de educação profissional, mediante a criação de novas unidades de ensino por parte da União, ocorrerá, preferencialmente, em parceria com Estados, Municípios, Distrito Federal, setor produtivo ou organizações não governamentais ${ }^{4}[\ldots]^{\prime \prime}$ (BRASIL, 1994, grifo nosso).

O termo "preferencialmente", o qual substituiu o termo "somente", foi considerado um marco histórico, pois, até 2002, haviam sido construídas 140 escolas técnicas federais no país, as quais ofertavam 113 mil matrículas, aponta o Relatório de Gestão SETEC/MEC do ano de 2011 (BRASIL, 2012, p. 50). Com a expansão ocorrida de 2005 a 2010, foram construídas mais 214 escolas técnicas, atendendo cerca de 132 mil alunos matriculados nas unidades recém implantadas (BRASIL, 2012, p. 12).

A criação dos Institutos Federais de Educação, Ciência e Tecnologia (IFETs), por meio da Lei 11.892, de 2008, também é considerada um avanço na história da EPT, por priorizar a formação técnica de nível médio de forma integrada com o ensino médio, como segue textualmente no Art. $7^{\circ}$ :

Art. $7^{\circ}$ Observadas as finalidades e características definidas no Art. $6^{\circ}$ desta Lei, são objetivos dos Institutos Federais: I- ministrar educação profissional técnica de nível médio, prioritariamente na forma de cursos integrados, para os concluintes do ensino fundamental e para o público da educação de jovens e adultos; II- ministrar cursos de formação inicial e continuada de trabalhadores, objetivando a capacitação, o aperfeiçoamento, a especialização e a atualização de profissionais, em todos os níveis de escolaridade, nas áreas da educação profissional e tecnológica; [...] (BRASIL, 2008).

O Decreto n. 5.154/2004, assim como a Lei 11.892/2008, funcionam como uma mediação do Estado para atender aos interesses de grupos distintos: dos que clamavam por uma educação profissional integrada ao ensino médio que se aproximasse de uma politecnia, vislumbrando o trabalho como princípio educativo, e uma educação unitária, como os intelectuais progressistas da educação, destacadamente, Demerval Saviani, Gaudêncio Frigotto, Marise Ramos, Maria Ciavatta e Acácia Kuenzer.

\footnotetext{
${ }^{4}$ Alterado pelo Art. $1^{\circ}$ da Lei n. 11.195, de 18 de novembro de 2005.
} 
Em 2007, é lançado o Sistema Escola Técnica Aberta do Brasil (e-Tec Brasil), por meio do Decreto n. 6.301, com "vistas ao desenvolvimento da educação profissional técnica na modalidade de educação a distância, com a finalidade de ampliar a oferta e democratizar o acesso a cursos técnicos de nível médio, públicos e gratuitos no país" (Art. $1^{\circ}$ ). O Sistema e-Tec Brasil foi uma articulação conjunta que envolveu a SETEC e Secretaria de Educação a Distância (SEED), com objetivo principal de "expandir e democratizar a oferta de cursos técnicos de nível médio, especialmente para o interior do País e para a periferia das áreas metropolitanas" (BRASIL, 2007).

É importante destacar que o e-Tec Brasil é parte das ações do PDE, que prevê "educação profissional integrada, em especial ao ensino médio, é a que apresenta melhores resultados pedagógicos ao promover o reforço mútuo dos conteúdos curriculares, inclusive na modalidade à distância" (BRASIL, 2007, p. 34).

Outra ação voltada para educação profissional do governo Luiz Inácio Lula da Silva (2003-2010) foi o Programa Brasil Profissionalizado, estabelecido por meio do Decreto 6.302, de dezembro de 2007, foi considerado por (CIAVATTA; RAMOS, 2011), como a primeira iniciativa do governo para fomentar a educação profissional no modelo integrado nas redes públicas estaduais e municipais, sem a participação de entidades civis, o que se afastava dos interesses de organismos internacionais e do que genericamente se chama de políticas neoliberais. A finalidade desse programa é "[...] estimular o ensino médio integrado à educação profissional, enfatizando a educação científica e humanística, por meio da articulação entre formação geral e educação profissional no contexto dos arranjos produtivos e das vocações locais e regionais" (BRASIL, 2007, p. 1).

Trata-se, na visão de Frigotto (2012, p. 74), de uma formação humana que visa romper com ensino dual, e também com as dicotomias gerais e específicas; ou seja, educação básica e técnica, que tem origens no pensamento positivista e fragmentário da realidade humana.

Esse programa, sob a tutela do MEC, compõe as metas do PDE que prevê:

Financiamento e assistência técnica para atender 750 escolas e 500 municípios, matricular 800 mil alunos, qualificar 14 mil professores e construir 2500 laboratórios, com um investimento de 800 milhões, no período 20082011. (BRASIL, 2011).

Concordamos com Ciavatta e Ramos (2011), quando defendem que esse programa viria aumentar a oferta de educação profissional integrada ao ensino 
médio nas redes estaduais de ensino, pois proporcionava assistência financeira por parte do Governo Federal às secretarias estaduais e municipais de educação, principalmente no que se refere à construção de novas escolas e melhorias de estruturas preexistentes, como bibliotecas, laboratórios, além disso os recursos, também poderiam ser investidos na formação de professores, técnicos e gestores para atuação nas unidades ofertantes de educação profissional.

Os resultados do Programa Brasil Profissionalizado, na visão de Pacheco e Morigi (2012, p. 102), apontam para uma ampliação do número de escolas que ofertam educação profissional e tecnológica integrada ao ensino médio nas redes estaduais e municipais de ensino, e consequentemente o aumento do número de matrículas. As classes dominadas tiveram ganhos nos níveis de qualidade da educação pela ampliação da oferta desse modelo de Educação Profissional e Tecnológica (EPT), integrada ao ensino médio.

Concordamos com a interpretação de Ramos (2014), acerca das contradições que ocorrem dentro do Estado. Para essa autora, o bloco no poder não opera de forma perfeitamente unida, sem divisões ou contradições, em vez disso organiza- se como uma "unidade conflitual de interesses, o que acaba por inscrever, de forma subordinada, as classes dominadas na materialidade institucional do Estado, ao passo que medidas materiais positivas são necessárias para a reprodução da hegemonia do bloco no poder" (RAMOS, 2014, p. 20-1).

Podemos observar, como exemplo desse conflito de interesses, o disposto no Art. $3^{\circ}$ do Decreto n. 6.094/2007, que institui o Programa Brasil Profissionalizado, o qual atrelou à participação dos Estados e Municípios a adesão formal ao Plano de Metas Compromisso Todos pela Educação, de que trata o Decreto no 6.094, de 24 de abril de 2007 (BRASIL, 2007). Isso significava que os recursos poderiam ser destinados, também, a entidades civis de ensino que ofertassem "cursos de nível técnico na forma subsequente, destituindo, então, o foco anteriormente definido, que era centrado na oferta de ensino médio integrado" (CÊA; SILVA, 2013, p. 7). Esse fato se deve, na visão de Ciavatta e Ramos (2011), à força que a classe empresarial possui tanto na sociedade civil quanto na política.

Acreditamos que o Brasil profissionalizado foi fruto de uma fissura do bloco que estava no poder, inicialmente, se constituiu em um caso de contradição existente na correlação de forças entre as classes e as frações de classe. Porém foi ajustado por pressão do empresariado nacional alterando o texto do Decreto 
n. 6.094/2007, para fomentar parcerias com as entidades civis, o que alterou o sentido original do Programa Brasil Profissionalizado.

A forte influência que os empresários exercem nas políticas públicas vem da força que seus representantes possuem junto ao aparelho do Estado, em que estão presentes seus representantes, os quais formam uma fração da burguesia no poder. Esse grupo age no aparelho do estado subordinando as políticas públicas aos seus próprios interesses, sobre esse modelo de Estado, Gramsci (1991, p. 50) afirma:

O Estado é concebido como organismo próprio de um grupo, destinado a criar condições favoráveis à expansão máxima desse grupo. [...] O grupo dominante coordena-se concretamente com os interesses gerais dos grupos subordinados, e a vida estatal é concebida como uma contínua formação e superação de equilíbrios instáveis (no âmbito da lei) entre os interesses do grupo fundamental e os interesses dos grupos subordinados [...].

Sobre essa influência do Grupo dos empresários para se mudar a essência do programa Brasil Profissionalizado, Cêa e Silva (2013) asseveram que esse fato tem ligação com o Plano de Metas Compromisso Todos pela Educação, "de projeto orientado pelo pensamento empresarial, envolvendo inúmeras entidades da sociedade civil, o Plano de Metas Compromisso Todos Pela Educação torna-se política de Estado" (CÊA; SILVA, 2013, p. 8).

A respeito do acordo de gratuidade entre o Governo Federal e o Sistema S cabe, antes de tudo, esclarecer que, nesse sistema, há um conjunto de entidades corporativas sem fins lucrativos, de interesse público e de direito privado, e que, por ter suas atividades subsidiadas pelo Estado, têm obrigatoriedade de oferecer vagas em cursos de qualificação de forma gratuita. O Sistema $\mathrm{S}$ tem por atividade fim, primordialmente o treinamento e qualificação de força de trabalho para atender demandas da indústria por meio do Serviço Nacional de Aprendizagem Industrial (SENAI); do comércio, por meio do Serviço Nacional de Aprendizagem do Comércio (SENAC); de atividades rurais por meio do Serviço Nacional de Aprendizagem Rural (SENAR); de atividades ligadas à formação de cooperativas por meio do Serviço Nacional de Aprendizagem do Cooperativismo (SESCOOP); além do Serviço Social do Comércio (SESC); Serviço Social da Indústria (SESI); Serviço Social de Transporte (SEST).

Para ampliar o oferecimento de vaga gratuita em cursos profissionalizantes oferecidas pelo Sistema S, o Ministro da Educação Fernando Haddad ${ }^{5}$, em nego-

\footnotetext{
${ }^{5}$ Foi ministro da educação entre julho de 2005 e janeiro de 2012, nos governos Luiz Inácio Lula da Silva e Dilma Rousseff.
} 
ciação com as confederações patronais, notadamente da indústria e do comércio, conseguiu um acordo que ampliava a destinação dos recursos administrados pelo Sistema S na oferta de atendimento de trabalhadores e estudantes pobres (BRASIL, 2014, p. 24).

Esse acordo de gratuidade se traduz em dois Decretos federais, o Decreto $n$. 6.633, de 5 de novembro de 2008, que alterou as regras do Regimento do Serviço Nacional de do Comércio (SENAC); e o Decreto n. 6.635, de 5 de novembro de 2008, que alterou as regras do Regimento do Serviço Nacional de Aprendizagem Industrial (SENAI). Isso resultou em modificações em regimentos que não sofriam qualquer alteração desde 1962.

Nos dois Decretos que alteram os regimentos do SENAC e do SENAI, ficou estabelecido que os cursos de Formação Inicial e Continuada (FIC) teriam uma carga horária mínima de 160 horas. Além disso, ficou acordado que essas entidades aumentariam gradativamente a aplicação de suas receitas líquidas na oferta de vagas gratuitas nos cursos de formação para estudantes de baixa renda e trabalhadores, empregados ou desempregados, chegando a dois terços até 2014 (BRASIL, 2014, p. 44-5).

O interesse da esfera privada em ter o Estado como aliado para promover a qualificação dos jovens, adaptando-os ao mundo do trabalho nessa fase de acumulação flexível do capital, se efetua por meio das políticas de "Estado educador" teorizado por Gramsci (1991) , o qual tem por finalidade "adequar a 'civilização' e a moralidade das mais amplas massas populares às necessidades de desenvolvimento continuado do aparelho econômico de produção, portanto, elaborar também fisicamente tipos novos de humanidade" (GRAMSCI, 1991, p. 91).

Isso perpassa, também, por uma relação de atendimento por parte dos governantes às demandas das classes dirigentes, representa em maior número por grupos de empresários. Sob esta ótica, Gramsci estabelece sua concepção de Estado, como "todo o complexo de atividades práticas e teóricas com as quais a classe dirigente justifica e mantém não só o seu domínio, mas consegue obter o consentimento ativo dos governados" (GRAMSCl, 1991, p. 91).

Para Kuenzer (2006, p. 899), as políticas e propostas contidas nos decretos e planos acima referenciados, nos dois governos, "não se diferenciam no que diz respeito à concepção das relações entre Estado e Sociedade Civil, que passam a se dar por meio das parcerias entre o setor público e o setor privado". 
O que percebemos foi a retomada da primazia do Estado em elaborar as políticas para educação; embora tenha estendido suas diretrizes ao setor privado, "sinaliza um dos principais aspectos de práxis de novo modelo de desenvolvimento" (FREITAS; SILVA, 2016, p. 74).

No âmbito do Estado ampliado de Gramsci (1991), a sociedade política nacional incorpora na Política de Educação Profissional concepções hegemônicas, baseadas nas competências.

\section{CONSIDERAÇÕES FINAIS}

Os ditames da nova fase de acumulação flexível do capital chegam fortemente ao Brasil, influenciando a política econômica e social no início da década de 1990. Os rearranjos políticos jurídicos e ideológicos acontecidos nessa década alinharam as políticas educacionais brasileiras à nova fase de acumulação flexível do capital, destacadamente, os representantes do empresariado e os organismos internacionais multilaterais como Banco Mundial, FMI e outros influenciando, em certa medida, a LDBEN 9.394/1996, assim como as políticas para a educação profissional.

A partir do exposto, observamos que os governos Fernando Henrique Cardoso (1995-2002) e Luiz Inácio Lula da Silva (2003-2010) conduziram suas políticas de EPT em atendimento às demandas das massas produtivas por acesso à qualificação, assim como, em atendimento aos interesses do sistema capitalista de produção representado externamente pelos organismos internacionais e internamente pelos grupos organizados de empresários. Isso confirma que, no Brasil, o grupo no poder medeia uma correlação de forças, que vem se mostrando desigual, tendendo ao atendimento dos interesses das classes dominantes.

Essas políticas públicas voltadas à educação profissional tornaram-se elemento importante na dimensão política e ideológica, servindo de estratégia da luta de classes; assim, a política do Estado vem garantindo a manutenção das relações de produção e divisão social do trabalho nessa fase de acumulação flexível do capital.

\section{REFERÊNCIAS}

ADRIÃO, Theresa. Educação e produtividade: a reforma do ensino paulista e a desobrigação do Estado. São Paulo: Xamã, 2006.

BALL, Stephan. Reformar escolas/reformar professores e os terrores da performatividade. Revista Portuguesa de Educação, Braga, Portugal, v. 15, n. 02, p. 3-23, 2002. 
BANCO MUNDIAL. Prioridades y estratégias para la educación. Washington: World Bank, 1995.

BRASIL. IPEA. PRONATEC: múltiplos arranjos e ações para ampliar o acesso à educação profissional. Texto para discussão. Brasília/Rio de Janeiro: Ipea, 2014.

BRASIL. Decreto n. 7.589, de 26 de outubro de 2011. Institui a Rede e-Tec Brasil. Disponível em: http://www.planalto.gov.br/ccivil_03/_Ato2011-2014/2011/Decreto/D7589.htm.

BRASIL. Ministério da Educação. Secretaria de Educação Profissional e Tecnológica. Prestação de Contas Ordinária: relatório de gestão 2011. Brasília, 2012. Disponível em: http://portal.mec.gov.br/index.php?option=com_docman\&view=download\&alias=10635relatorio-gestao-setec-2011-pdf\&category_slug=abril-2012-pdf\&Itemid=30192. Acesso em: 22 maio 2015.

BRASIL. Decreto n. 6.635, de 5 de novembro de 2008. Altera e acresce dispositivos ao Regimento do Serviço Nacional de Aprendizagem Industrial - SENAl, aprovado pelo Decreto no 494, de 10 de janeiro de 1962. Disponível em: http://www.planalto.gov.br/ ccivil_03/_Ato2007-2010/2008/Decreto/D6635.htm.

BRASIL. Decreto n. 6.633, de 5 de novembro de 2008. Altera e acresce dispositivos ao Regulamento do Serviço Nacional de Aprendizagem Comercial-SENAC, aprovado pelo Decreto no 61.843, de 5 de dezembro de 1967. Disponível em: http://www.planalto.gov. br/ccivil_03/_Ato2007-2010/2008/Decreto/D6633.htm.

BRASIL. Lei n 11.892, de 29 de dezembro de 2008. Institui a Rede Federal de Educação Profissional, Científica e Tecnológica. In: SILVA, Caetana Juraci Rezende; VIDOR, Alexandre Martins; PACHECO, Eliezer Moreira; PEREIRA, Luiz Augusto Caldas (Org.). Comentário e reflexões. Brasília, DF, 2008.

BRASIL. O Plano de Desenvolvimento da Educação: razão, princípios e programas - PDE. Brasília: Ministério da Educação, 2007.

BRASIL. Decreto n. 6.094, de 24 de abril de 2007. Dispõe sobre a implementação do Plano de Metas Compromisso Todos pela Educação. Disponível em: http://www. planalto.gov.br/ccivil_03/_ato2007-2010/2007/decreto/d6094.htm. Acesso em: 22 maio 2015.

BRASIL. Decreto n. 6.302, de 12 de dezembro de 2007. Institui o Programa Brasil Profissionalizado. 2007. Disponível em: http://www.planalto.gov.br/ccivil_03/_Ato20072010/2007/Decreto/D6302.htm. Acesso em. 10 ago. 2013 
BRASIL. Decreto n. 6.301, de 12 de dezembro de 2007. Institui o Programa Brasil Profissionalizado. Revogado pelo Decreto n. 7.589, de 2011. Diário Oficial da União, Brasília, 13 de dezembro de 2007. Disponível em: http://www.planalto.gov.br/ccivil_03/_ Ato2007-2010/2007/Decreto/D6301.htm. Acesso em. 10 ago. 2013.

BRASIL. Lei n. 11.195, de 18 de novembro de 2005. Dá nova redação ao § 50 do art. 30 da Lei no 8.948, de 8 de dezembro de 1994. Diário Oficial da União, Brasília, 18 de novembro de 2005, edição extra. Disponível em: http://www.planalto.gov.br/ccivil_03/_Ato20042006/2005/Lei/L11195.htm.

BRASIL. Decreto n. 5.154, de 23 de julho de 2004. Regulamenta o art. 36 e os artigos 39 a 41 da Lei n. 9394/1996. Senado Federal. Subsecretaria de Informações. Disponível em: https://www.camara.leg.br/proposicoesWeb/prop_mostrarintegra;jsessionid=C9E3A9F5 9D3FF289BDA772DC930895E5. proposicoesWeb1 ?codteor=546212\&filename=Legislac aoCitada+-PL+3053/2008. Acesso em: 28 mar. 2015.

BRASIL. Ministério do Trabalho e do Emprego. PLANFOR. Avaliação gerencial 1995/98: balanço de um projeto para o desenvolvimento sustentado. Brasília: SEFOR, 1999.

BRASIL. Ministério do Trabalho e do Emprego. Plano Nacional de Qualificação do Trabalhador-PLANFOR: reconstruindo a institucionalidade da educação profissional no Brasil. Brasília, 1998.

BRASIL. Lei n. 9.649, de 27 de maio de 1998. Dispõe sobre a organização da Presidência da República e dos Ministérios, e dá outras providências. Disponível em: http://www. planalto.gov.br/ccivil_03/leis/L9649cons.htm.

BRASIL. Decreto n. 2.208, de 17 de abril de 1997. Regulamenta o art. 36 e os artigos 39 a 42 da Lei n. 9394/96. Diário Oficial da União, Brasília, 18 de abril de 1997, seção 1, p. 7760.

BRASIL. Lei n. 9.394, de 20 de dezembro de 1996. Estabelece as diretrizes e bases da educação nacional. Brasília, 1996. Disponível em: http://www.planalto.gov.br/ccivil_03/ LEIS/L9394.htm. Acesso em: 22 maio 2015.

BRASIL. Lei n. 8.948, de 8 de dezembro de 1994. Dispõe sobre a instituição do Sistema Nacional de Educação Tecnológica e dá outras providências. Disponível em: http://www. planalto.gov.br/ccivil_03/leis/L8948.htm. Acesso em: 15 jun. 2012.

BREMER, Maria Aparecida S.; KUENZER, Acácia Z. Ensino médio integrado: uma história de contradições. In: SEMINÁRIO DE PESQUISA EM EDUCAÇÃO DA REGIÃO SUL- ANPED SUL, 9., 2012, Caxias do Sul, RS. Anais [...] Caxias do Sul, RS: UCS, 2012. Disponível em: http:// 
www.ucs.br/etc/conferencias/index.php/anpedsul/9anpedsul/paper/viewFile/2217/208. Acesso em: 20 dez. 2015.

BRESSER-PEREIRA, Luiz Carlos. Do antigo ao novo desenvolvimentismo na América Latina. Textos para Discussão n. 274, São Paulo, FGV, p. 1-38, nov. 2010.

CÊA, Georgia Sobreira dos Santos; SILVA, Camila Ferreira. O Programa Brasil Profissionalizado como uma das expressões do neoliberalismo nos governos Lula da Silva e Dilma Rousseff. In: CONGRESSO LATINO AMERICANO DE SOCIOLOGIA, 29.,2013. Anais [...]. Santiago, Chile: Ed. ALAS (Asociación Latinoamericana de Sociología), 2013. v. 1, p. 1-11.

CIAVATTA, Maria; RAMOS, Marise. Ensino Médio e Educação Profissional no Brasil: Dualidade e Fragmentação. Revista Retratos da Escola, Brasília, v. 5, n. 8, p. 27-41, jan./ jun. 2011. Disponível em: http://retratosdaescola.emnuvens.com.br/rde/article/view/45. Acesso em: 20 dez. 2015.

CONFEDERAÇÃO NACIONAL DA INDÚSTRIA. Educação básica e formação profissional: uma visão dos empresários. Rio de Janeiro: CNI, 1993.

CONFERÊNCIA Mundial de Educação para Todos. Declaração Mundial de Educação para Todos. Plano de Ação para Satisfazer as Necessidades Básicas de Aprendizagem. Brasília, DF: UNIFEC, 1990.

DEITOS, Roberto Antonio. O capital financeiro e a educação no Brasil. 2005. 357f. Tese (Doutorado em Educação)- Universidade Estadual de Campinas (UNICAMP), Campinas, SP, 2005.

DELORS, Jacques. Educação: um tesouro a descobrir. Relatório para a UNESCO da Comissão Internacional sobre Educação para o século XXI. São Paulo: Cortez; Brasília, DF: MEC: UNESCO, 1998.

FREITAS, Cecília C. S.; SILVA, Marcelo S. P. O Plano de Desenvolvimento da Educação no contexto do novo desenvolvimentismo brasileiro. Revista Brasileira de Política e Administração da Educação - RBPAE, Goiânia, GO, v. 32, n. 1, p. 69-88, jan./abr. 2016.

FRIGOTTO, Gaudêncio. Concepções e mudanças no mundo do trabalho e o Ensino Médio. In: FRIGOTTO, Gaudêncio; CIAVATTA, Maria; RAMOS, Marise (Org.). Ensino médio integrado: concepções e contradições. 3. ed. São Paulo: Cortez, 2012. p. 57-82.

FRIGOTTO, Gaudêncio; CIAVATTA, Maria; RAMOS, Marise. A Gênese do Decreto n. 5.154/2005: um debate no contexto controverso da democracia restrita. In: FRIGOTTO, 
Gaudêncio; CIAVATTA, Maria; RAMOS, Marise (Org.). Ensino médio integrado: concepções e contradições. 3. ed. São Paulo: Cortez, 2012. p. 21-56.

FRIGOTTO, Gaudêncio; CIAVATTA, Maria; RAMOS, Marise (Org.). Ensino Médio Integrado - concepções e contradições. São Paulo: Cortez, 2005.

GRAMSCI, Antonio. Os intelectuais e a organização da cultura. Rio de Janeiro: Civilização Brasileira, 1991.

KUENZER, Acacia Zeneida. A educação profissional nos anos 2000: a dimensão subordinada das políticas de inclusão. Educação \& Sociedade, Campinas, SP, v. 27, n. 96- Especial, p. 877-910, out. 2006.

MELO, Alessandro de. O projeto pedagógico da Confederação Nacional da Indústria para a educação básica nos anos 2000. 2010. Tese (Doutorado em Educação) - Universidade Federal do Paraná (UFPR), Curitiba, 2010.

MERCADANTE OLIVA, Aloizio. As bases do novo desenvolvimentismo no Brasil: análise do governo Lula (2003-2010). 2010. Tese (Doutorado em Ciências Econômicas)- Universidade Estadual de Campinas (UNICAMP), Campinas, SP, 2010.

MORAIS, Lecio; SAAD-FILHO, Alfredo. Da economia política à política econômica: o novodesenvolvimentismo e o governo Lula. Revista de Economia Política, São Paulo, v. 31, n. 4, p. 507-27, out./dez. 2011.

MOURA, Dante H. Educação Básica e Educação Profissional e Tecnológica: dualidade histórica e perspectivas de integração. Holos, Natal, RN, ano 23, v. 2, p. 4-30, 2007.

OFFE, Claus. Sistema educacional, sistema ocupacional e política da educação: contribuição à determinação das funções sociais do sistema educacional. Educação \& Sociedade, Campinas, SP, v. 11, n. 35, p. 9-59, abr. 1990.

OLIVEIRA, Dalila Andrade. As políticas educacionais no governo Lula: rupturas e permanências. Revista Brasileira de Política e Administração da Educação - RBPAE, Goiânia, GO, v. 25, n. 2, p. 197-209, maio/ago. 2009.

PACHECO, Eliezer Moreira; MORIGI, Valter (Org.). Ensino técnico, formação profissional e cidadania. Porto Alegre, RS: Tekne, 2012.

POCHMANN, Marcio. Estrutura social no Brasil: mudanças recentes. Serviço Social \& Sociedade, São Paulo, n. 104, p. 637-49, out./dez. 2010. DOI: http://dx.doi.org/10.1590/ S0101-66282010000400004 
RAMOS, Marise. Educação tecnológica como política de Estado. In: OLIVEIRA, Ramon de (Org.). Jovens, ensino médio e educação profissional: políticas públicas em debate. Campinas, SP: 2012. p. 9-46.

RAMOS, Leandro da Fonseca. O Pronatec como Política Governamental para Educação Profissional: historicidade e contradições na construção de uma política para Educação Profissional. 2014. 116 f. Dissertação (Mestrado Educação Profissional em Saúde) Fundação Oswaldo Cruz, Rio de Janeiro, 2014.

SILVA, M. R. Currículo e competências: a formação administrada. São Paulo: Cortez, 2007.

SHIROMA, Eneida Oto; MORAES, Maria Célia Marcondes de; EVANGELISTA, Olinda. (Org.). Política educacional. Rio de Janeiro: Lamparina, 2002.

\section{Sobre os autores:}

Arão Davi Oliveira: Doutorando do Programa de Pós-graduação em EducaçãoMestrado e Doutorado- da Universidade Católica Dom Bosco (UCDB). Professor na graduação em Pedagogia do Centro Universitário Anhanguera, Campo Grande, MS, também, da Faculdade Campo Grande (FCG), MS. Membro do Grupo de Pesquisa Políticas de Formação e Trabalho Docente na Educação Básica, vinculado ao PPGE/UCDB, e do Grupo de Pesquisa Políticas Públicas Educacionais no âmbito da Educação Básica, vinculado ao PPGE/UCB/DF. Bolsista de Doutorado da Coordenação de Aperfeiçoamento de Pessoal de Nível Superior (CAPES), Brasil. E-mail: adodavi@gmail.com

Celeida Maria Costa de Souza e Silva: Doutora em Educação. Professora Pesquisadora do Programa de Pós-Graduação em Educação - Mestrado e Doutorado - da Universidade Católica Dom Bosco (UCDB), MS. Líder do Grupo de Pesquisa Políticas de Formação e Trabalho Docente na Educação Básica, vinculado ao PPGE/UCDB, e Vice-líder do Grupo de Pesquisa Políticas Públicas Educacionais no âmbito da Educação Básica, vinculado PPGE/UCB/DF. E-mail: celeidams@uol.com.br

\section{Recebido em março de 2018 Aceito em dezembro de 2018}

